\title{
ADAPTAÇÃO AOS CENÁRIOS IMPONDERÁVEIS DA VARIABILIDADE CLIMÁTICA
}

\author{
ADAPTACIÓN A LOS ESCENARIOS IMPONDERABLES DE LA \\ VARIABILIDAD CLIMÁTICA
}

\author{
ADAPTATION TO IMPONDERABLES SCENARIOS OF CLIMATIC \\ VARIABILITY
}

Sérgio Almeida LOIOLA ${ }^{1}$

RESUMO: Este artigo é uma contribuição aos debates sobre as alternativas diante de mudanças climáticas extremas e catástrofes globais extremas e abruptas. Propõe a construção de três planos simultâneos para as sociedades lidarem com as alterações extremas e abruptas do clima e catástrofes globais extremas, centrados na busca da adaptação pró-ativa, ou sustentabilidade adaptativa aos cenários imponderáveis: Plano A, voltado ao aquecimento global; Plano B, dedicado ao resfriamento global; e Plano C, para casos de instabilidade climática. Pauta-se em dados e informações paleoclimáticas globais, analisados sob metodologia comparativa. Os planos justificam-se no argumento da imponderabilidade climática no curto, médio e longo tempo, fundamentada na Teoria do Caos e do Erro, bem como análises dos gráficos de temperatura, gases estufa, energia solar e outras variáveis, sobretudo durante o Pleistoceno. Sustenta-se que, embora não se possa prever o clima e ou catástrofes futuras, pode-se aprender com as ocorrências no passado, resgatar os saberes elaborados por diferentes civilizações durante o Holoceno e períodos anteriores, em respostas às alterações climáticas extremas e catástrofes abruptas extremas, tanto seus erros quanto acertos.

Palavras chaves: Adaptação, Teoria do Caos, paleoclimatologia, mudanças climáticas.

\footnotetext{
${ }^{1}$ Resultados de pesquisa de Doutorado, Instituto de Estudo Socioambientais IESA, Universidade Federal de Goiás - UFG, Goiás, Brasil. Orientadora: Profa. Dra. Sandra de Fátima Oliveira. Co-orientadora: Profa. Dra. Maria Nazaré Stevaux. Mestre em Geografia, IESA, UFG (2007). Investiga a Estruturação de Sistemas Complexos Adaptativos e a Evolução de Sistemas Cognitivos em sociedades humanas frente à variação climática, envolvendo a perspectiva complexa. Dedica-se ao desenvolvimento de teoria e método complexo na geografia, implicações dos avanços da física teórica, biologia e de diversas ciências para integrar a Complexidade, e a pesquisa da interação paleoclima, sociedade, sustentabilidade e adaptação. Integrante do Núcleo de Pesquisas Transdisciplinares e Educação Ambiental - NUPEAT, IESA, UFG. Integrante da Escola da Complexidade - http://complexidade.ning.com/. Coordenador do Conselho Científico da Revista Terceiro Incluído - Bolsa da CAPES sergioaloiola@gmail.com
} 
RESUMEN: Este artículo es una contribución a los debates sobre las alternativas ante los cambios climáticos y desastres globales extremos y abruptos. Propone la construcción de tres planes simultáneos para extremos y abruptos cambios de clima y desastres extremos mundiales, centrándose en la búsqueda de adaptación proactiva o adaptables, sostenibilidad a escenarios probables: plan A, orientada al calentamiento global; Plan B, dedicado al enfriamiento global; y el plan C, para los casos de inestabilidad del clima global. Con base en datos paleoclimáticos globales, analizados bajo la metodología comparativa, Los planes se justifica en el argumento de imponderabilidad climático en el corto, mediano y largo plazo, que se muestran en la Teoría del Caos y Error, en el análisis de los gráficos de temperatura, los gases de efecto invernadero, solar y otras variables, especialmente durante el Pleistoceno. Por lo tanto, se argumenta que, aunque no podemos predecir el clima o los desastres y futuros, pueden aprender de los acontecimientos en el pasado, para rescatar los conocimientos producidos por las diferentes civilizaciones durante los períodos del Holoceno y antes, en respuesta a los cambios climáticos extremos desastres repentinos y extremos, tanto de sus errores como éxitos.

Palabras-clave: Adaptación, Teoría del caos, paleoclimatología, cambio climático.

\begin{abstract}
This article is a contribution to debates about the alternatives in the extremes climate change and global catastrophes sudden and extreme. Proposes the construction of three simultaneous planes for to work with climate change, focusing on the pursuit of proactive adaptation, or Adaptive sustainability to the imponderables scenarios: Plan A, focused on global warming, Plan B, dedicated to global cooling, and Plan C in case of climatic instability. Based in global paleoclimatic data, analyzed under comparative methodology. The plans are justified in the argument of imponderability climatic in the short, medium and long time, based on the Chaos Theory and Error, as evidenced in the analysis of temperature charts, greenhouse gases, solar and other variables, especially during the Pleistocene. Thus, it is argued that, although we cannot predict the future climate, we can learn from the variations in the past, to rescue the knowledge produced by different civilizations during the Holocene and earlier periods, in response to extreme climate change and global catastrophes sudden and extreme, both its errors as hits.
\end{abstract}

Key words: Adaptation, Chaos Theory, paleoclimatology, climate change. 


\section{INTRODUÇÃO}

"A criação é imperfeita." Marcelo Glaiser ${ }^{2}$

"Na natureza, sistemas afastados do equilíbrio, não lineares e a incerteza são a regra e não a exceção" Ilya Prigogine ${ }^{3}$

São crescentes os esforços de pesquisa e políticas direcionadas à problemática climático-ecológicas, sobretudo a partir das indicações de cenários a um possível aquecimento global, em média de 2 a $6{ }^{\circ} \mathrm{C}$, até o final deste século XXI, apontado pelos relatórios do IPCC (2009). ${ }^{4}$ Porém, os esforços concentram-se em duas frentes, a previsão e a mitigação, enquanto pouca atenção é dada a adaptação. De um lado, os debates acadêmicos e políticos concentram-se em avaliar o grau de contribuição das atividades humanas na elevação dos níveis dos gases estufa, e estabelecer prováveis cenários para as alterações climáticas futuras. De outro, a comunidade internacional empenha-se em procurar alternativas para reduzir a emissão de gases estufa, a fim de mitigar os efeitos do aquecimento global, enfatizando tecnologias que descarbonizem a economia.

Entretanto, pouca atenção tem sido dada à necessidade de as sociedades se prepararem para a variabilidade climática, seja aquecimento, resfriamento, seja seca ou chuvas extremas, já que a principal certeza investigada em nossas pesquisas sobre a variação do clima global no passado é a sua variação, cíclica, aleatória, abrupta ou induzida, suave ou extrema, no curto, médio ou longo prazo. É necessário ir além do estabelecimento de cenários e das medidas mitigadoras a um provável aquecimento, e gerar políticas, protocolos, tecnologias e a difusão de conhecimentos orientados à redução da vulnerabilidade climática, enfatizando a adaptação aos cenários previstos e não previstos, sejam eles de aquecimento, resfriamento global ou de instabilidade climática.

${ }^{2}$ Físico teórico e astrônomo brasileiro.

${ }^{3}$ Físico Químico russo. Nobel de química, 1977.

${ }^{4}$ IPCC : Intergovernmental Panel on Climate Change 


\section{OBJETIVO}

O objetivo é, a partir das indicações da imprevisibilidade dos sistemas climáticos verificados nas pesquisas em paleoclima, propor um programa global denominado Painel da Sustentabilidade Adaptativa para dotar as sociedades de uma estrutura supranacional, independente, composto por sociedade civil organizada, pesquisadores e instituições a fim de lidar com a adaptação as variações climáticas abruptas e severas, já que, no curto, médio e longo tempo, existe alto grau de incerteza acerca da dinâmica climática, a qual a torna imponderável.

\section{REFERENCIAIS TEÓRICO-METODOLÓGICOS}

As propostas aqui apresentadas fundamentam-se na tese de que a previsão climática é imponderável no curto, médio e longo prazo, a partir da Teoria do Erro e da Teoria do Caos. A Teoria do Erro na física expõe que a margem de erro em qualquer mensuração pode ser para mais ou para menos. Se as magnitudes das variáveis medidas são menores que o próprio erro dos instrumentos, pouco pode ser afirmado sobre cenários futuros.

Quanto a Teoria do Caos, durante 2000 anos a fenomenologia afastou da ciência a incerteza, o caos, o aleatório, criando uma flecha cartesiana arbitraria do tempo, entre passado e futuro, numa busca "religiosa" por certa idéia de ordem determinista aristotélica de equilíbrio no Universo. No entanto, nada tende ao equilíbrio, pois todos os sistemas são abertos.

Ordem e equilíbrio foram induzidos pela percepção humana. As rupturas epistemológicas das novas teorias da física, química e matemática do não-equilíbrio demonstram que a flecha do tempo existe, é irreversível, direcional, num fluir sem fim num movimento caótico predominante em $99,9 \%$ das leis naturais. Não somos nós que geramos flecha dom tempo. Porém, dela somos seus filhos, de modo que, não haveria vida na Terra sem a coerência dos processos irreversíveis de não-equilíbrio (PRIGOGINI, 1996, p. 11-12).

[...a matéria é cega ao equilíbrio ali onde a flecha do tempo não se manifesta, longe do equilíbrio, a matéria começa a ver! Sem a coerência dos processos irreversíveis de não-equilíbrio, o aparecimento da vida na Terra seria inconcebível. A tese de que a flecha do tempo é apenas fenomenológica é absurda. Não somos nós que geramos a flecha do tempo. Muito pelo contrário, somo seus filhos.” (PRIGOGINE, 1996, p. 11-12) 
Ao contrário dos postulados deterministas, as leis da natureza seguem caminhos caóticos em 99,9\% dos processos naturais, não podendo ser predita, de modo que, as leis da natureza: "não mais se assenta em certezas, como as leis deterministas, mas avança sobre possibilidades" (PRIGOGINI, 1996, p. 30-31).

Se as dinâmicas paleoclimática sugerem a imponderabilidade climática, não há motivo para pensar que cenários possíveis efetivamente ocorram como esboçados. Tal constatação informa que as sociedades são ainda mais vulneráveis as variações climáticoecológicas do que tem sido exposto nos relatórios do IPCC e na grande maioria das pesquisas sobre o clima global. Há nesse campo uma incerteza sombria, pouco revelada.

A constatação das alterações climáticas do passado distante, caracterizado por elevado grau de variáveis e combinações possíveis de sistemas abertos, seja na dinâmica dos sistemas de superfície, geotérmicos ou astronômicos, provieram da pesquisa de doutorado, cujo escopo visa demonstrar que muitas sociedades do passado souberam atravessar as variações climáticas, e desenvolveram sistemas complexos adaptativos, entendidos como sistemas cognitivos construídos ao longo da história para dar respostas as variações das intempéries: esquemas, ciclos celestiais, marcadores ambientais, saberes, métodos, metodologias, técnicas, ciência, comportamento, sistemas agrícolas, seleção de sementes, arquitetura, uso da energia, uso de metais, estruturas sociopolíticas, formação de nichos ecológicos, mitos etc.

Dada à capacidade de realizar sua autopoiese, cujo processo central é a cognição, pois viver é aprender (MATURANA E VARELA, 2005), as sociedades humanas elaboraram inúmeros sistemas complexos adaptativos ao longo de suas histórias em respostas as demandas sociais e variações climático-ecológicas. Para Gell-Mann (1996), o sistema imunológico, os sistemas econômicos, as ciências, os sistemas de crenças, os sistemas econômicos, a gestão de empresas e as organizações sociais seriam exemplos inequívocos da existência de sistemas complexos adaptativos.

Sistemas complexos adaptativos são estruturas cognitivas que evoluem. São respostas mentais intencionais que operam num padrão em rede, estruturadas num conjunto de argumentação coerente, com objetivos, método, formos de perceber, identificar e representar o mundo, codificar, compreender, criar modelos mentais, normas, esquemas e 
técnicas no sentido de dar soluções, escapar e/ou sobreviver diante das adversidades (GELL-MANN, 1996, p. 302-316).

Identificar tais sistemas possibilita perceber, codificar, criar modelos, desenvolver linguagens para representar e se relacionar com o mundo a fim de compreendê-lo, ou, nele intervir e sobreviver.

Sociedades antigas, tradicionais e modernas se relacionaram com seu entorno, atravessaram alterações climáticas e elaboraram saberes, sistemas de representação, valores, normas e técnicas para se alimentarem, protegerem, vestirem, habitarem e lidarem com as intempéries (CLAVAL, 1997, p. 114; SANTOS, 1997, p.37).

Para conhecer e compreender essas relações sociedade-natureza é preciso verificar a simultaneidade entre os recursos desenvolvidos em respostas às alterações climáticas no movimento histórico do espaço-tempo ambiental (LOIOLA, 2010a, 2011), o que requer especial atenção à dinâmica atmosférica. Assim, importa evidenciar as modificações climáticas no curto, médio e longo tempo.

\section{SOBRE A ATMOSFERA E SEUS RITMOS}

Composta de gases, poeira e microorganismos, a atmosfera comporta-se como um grande "oceano aéreo", interliga os demais sistemas terrestres no tempo e no espaço, supre os seres vivos de oxigênio, gás carbônico, e possui função central no transporte de água aos diferentes ecossistemas e no balanço térmico superficial do planeta (SANT'ANNA NETO \& NERY, 2005, p. 28).

Porém, como todos os sistemas abertos, a principal característica dos sistemas terrestres é o não-equilíbrio e de estar interligado com outros sistemas instáveis (PRIGOGINY, 1996; NOVELLO, 2010). A vida surgiu numa atmosfera redutora e caótica e, ela própria, com suas atividades modificou a atmosfera tornando-a oxidante. Essa alteração respondeu pela maior extinção da biodiversidade na história da vida - os organismos anaeróbicos, que dependiam da atmosfera redutora. Desse modo, instabilidade, não-equilíbrio e não-linearidade são atributos dos fenômenos atmosféricos, e dos sistemas vivos.

Resultante de uma complexa interação de fenômenos, processos e fatores astronômicos, geográficos, geotérmicos, químicos, físicos e biológicos, a dinâmica 
atmosférica segue afastada do equilíbrio. Apresenta alterações de estado diuturnas e sazonais nos elementos do tempo atmosféricos, entre eles umidade, vento, massas de ar, ciclones, precipitação, temperatura, nuvens e pressão, e modificações anuais, em décadas, séculos e milênios (AYOADE, 1996, p. 205).

Enquanto as alterações imediatas nos estados atmosféricos geram o tempo, observadas a partir das variáveis físicas temperatura, pressão, umidade, ventos, precipitação e massas de ar, a cadência rítmica de sucessão de tempos atmosféricos responde pelos padrões e ritmos climáticos na perspectiva geográfica (MENDONÇA \& DANNIOLIVEIRA, 2007, p. 15). Tributários de processos cíclicos ou não, os estados atmosféricos e os ritmos climáticos sofrem constantes alterações em diferentes escalas temporais e espaciais, caracterizando a variabilidade climática, cujo conhecimento é fundamental para as sociedades (SANT'ANNA NETO \& NERY, 2005, p. 29-30). Pois, desenvolver habilidades para lidar com a variabilidade climática é fator decisivo para a sobrevivência.

Assim, a variabilidade climática é a expressão das variações de clima em função dos condicionantes naturais do globo terrestre e suas interações externas, seja em escala diária ou milenar ( $2^{\circ}$ Framework Convention on Climate Change, ONU, 1990). A variabilidade climática significa a tendência de caráter cíclico ou aleatória do clima variar, sob uma conjunção de variáveis que nem sempre se agrupam de forma idêntica, tampouco são lineares, tais como os fenômenos ENSO, ODP e glaciações.

O significado da variabilidade climática informa que a principal certeza sobre o clima é a sua variação, cíclica, aleatória, abrupta ou induzida, no curto, médio ou longo prazo, sejam períodos de aquecimento ou resfriamento, secos ou chuvosos. Em certos períodos, fenômenos naturais, ou processos antrópicos, podem alterar a variabilidade climática natural. Neste caso, cabe falar de mudanças climáticas, que alteram significativamente os padrões do ritmo climático (JISAO, 2009).

\section{METODOLOGIA E FONTES}

Os planos fundam-se no argumento da imponderabilidade climática no longo tempo, evidenciada na análise dos gráficos de temperatura, gases estufa, energia solar e outras variáveis, sobretudo durante o Pleistoceno. Sustenta-se que, embora não se possa prever o clima futuro, pode-se aprender com as variações ocorridas no passado, resgatar os saberes 
de civilizações durante o Holoceno e períodos anteriores, em respostas às alterações climáticas, tanto seus erros quanto acertos.

A pesquisa entende os sistemas complexos adaptativos a partir de uma perspectiva cognitiva e evolutiva, utilizando-se de métodos comparativos, em uso na biologia comparada, para resgatar os passos evolutivos dos sistemas cognitivos em diferentes sociedades e épocas, em respostas as variações climáticas. Utiliza-se de diversas fontes bibliográficas e dados astronômicos, da história ambiental, da arqueologia, de paleoclima, da paleocologia, da geologia, etc. Entre as fontes cita-se:

APDRC - Asian Pacific Data Reserch Center. Modelos paleoclimáticos da APDRC CDC - CIRES - Climate Diagnostics Center - Cooperative Institute for Research for Environmental Science

CPTEC-INPE-- Centro de Previsão de Tempo e Estudos Climáticos. Instituto Nacional de Pesquisas Espaciais. ENOS. Disponível em: <http://enos.cptec.inpe.br/> Acessado: Agosto de 2009

CPTEC-INPE - Grupo de pesquisa em Mudanças Climáticas (GPMC). Disponível em: $<$ http://mudancasclimaticas.cptec.inpe.br>

ESRL - PSD - NOAA. Earth System Research Laboratory - Physical Sciences Division Multivariate ENSO Index (MEI). Disponível em:

<http://www.esrl.noaa.gov/psd/people/klaus.wolter/MEI/\#comparison> Acessado: Outubro de 2009.

GISS - NASA - Goddard for Spaces Studies - National Agency Space American

GSW - GeoScienceWorld - <http://www.geoscienceworld.org> Base de dados de geociências

INMET - Instituto Nacional de meteorologia

IPCC - Intergovernmental Panel on Climate Change. Disponivel em: 〈http://www.ipcc.ch/>

JISAO (Joint Institute For de Study of the Atmosphere e Clime).Monthily values for PDO Index: 1900 - Agosto de 2012. Diponível: <http://jisao.washington.edu/pdo/> Acessado: setembro de 2012.

NCDC - NOAA. National Climatic Data Center. National Oceanic Atmospheric Administration.

NOAA Paleoclimatology. Modelos paleoclimáticos NOAA paleocliamtology 
PANGAEA - Publishing Network for Geoscientific \& Environmental Data.

SWPC-NOAA. Solar Cycle Progression: Solar Cycle 24 prediction update released May 8, 2009. In: Space Weather Prediction Center, NOAA. Disponível em

<http://www.swpc.noaa.gov/SolarCycle/>

WDC-NOAA: World Data Center for Paleoclimatology.

$<$ http://www.ncdc.noaa.gov/paleo>

\section{ENTRE O PONDERÁVEL E O IMPONDERÁVEL}

Pesquisas indicam que alterações climáticas foram constantes no passado distante e recente da Terra, desde variações cíclicas e abruptas, moderadas e extremas (FLANERY, 2007, p.59; SALGADO-LABORIOU, 2007, p. 1; DIAMOND, 2005, p. 28; SANT'ANNA NETO \& NERY, 2005, p. 28; OLIVEIRA et al, 2005, p.52; SUGUIO et al, 2005, p. 114; KIPNIS \& SCHEEL-YBERT, 2005, p.353; LEWIN, 1999). É indispensável dotar as sociedades de recursos para conviver com as incertezas das alternâncias climáticas.

Alterações climáticas cíclicas e aleatórias requerem especial atenção, já que a recorrência de ambas permite estabelecer cenários, antecipar medidas, desenvolver técnicas, políticas e procedimentos para resguardar as sociedades.

Dentre os fenômenos climáticos cíclicos mais representativos no clima global e regional estão: o El Niño-Oscilação Sul (ENOS), a Oscilação Decadal do Pacífico (ODP), NAO - Oscilação Atlântico Norte, os ciclos de atividades solares e os ciclos longos na variação da geometria orbital da Terra, ou ciclos de Milankovitch (QUADRO 1).

\begin{tabular}{|l|l|l|}
\hline \multicolumn{1}{|c|}{ PERIODICIDADE } & \multicolumn{1}{c|}{ FENÔMENO } & \multicolumn{1}{c|}{ PRINCIPAIS ORIGENS } \\
\hline 6 a 18 meses & ENOS - El Niño - La Niña & Interações oceano-atmosfera \\
\hline 10 anos & NAO - Oscilação Atlântico Norte & Interações oceano-atmosfera \\
\hline 20 a 30 anos & ODP - Oscil. Decadal Pacífico & Interações oceano-atmosfera \\
\hline $11,22,44$ e 70 anos e séculos & Manchas solares & Astronômica - Atividade solar \\
\hline 18,6 Anos & Nutação & Astronômica - Oscilação Terra-Lua \\
\hline Mil a três mil anos & Ciclos Dansgaard-Oeschger & Interações criosfera-oceano-atmosfera \\
\hline Sete mil a treze mil anos & Eventos Heinrich & Interaçôes criosfera-oceano-atmosfera \\
\hline 11 mil e 22 mil anos & Precessão dos equinócios - Terra & Astronômica - Variação orbital - Terra \\
\hline 42 mil anos & Obliqüidade da eclíptica - Terra & Astronômica - Variação orbital - Terra \\
\hline 96 mil anos & Excentricidade orbital - Terra & Astronômica - Variação orbital - Terra \\
\hline
\end{tabular}

Quadro 1 - Periodicidade, fenômenos e origens de algumas variações climáticas 
Desse modo, a investigação tem por referência dinâmicas paleoclimáticas cíclicas e aleatórias. Mais que predizer cenários climáticos e adotar medidas mitigadoras é necessário ser pró-ativo na busca de limiares de adaptação às mudanças climáticas. A seguir são esboçadas variações climáticas cíclicas e não cíclicas no curto, médio e longo prazo. Observa-se que, mesmo os eventos cíclicos podem não se repetir.

Os ciclos de El Niño-Oscilação Sul resultam de uma combinação de fatores oceânicos e atmosféricos. Os ENOS possuem duas fases, uma fria e outra quente, que ocorrem em intervalos de 6 a 18 meses, mas entre um evento e outro podem transcorrer de 1 a 10 anos (FIGURA 1). Durante a ocorrência dos ENOS, diversas partes do globo experimentam alterações na distribuição pluviométrica e temperatura, sobretudo nas regiões tropicais e nas latitudes médias.

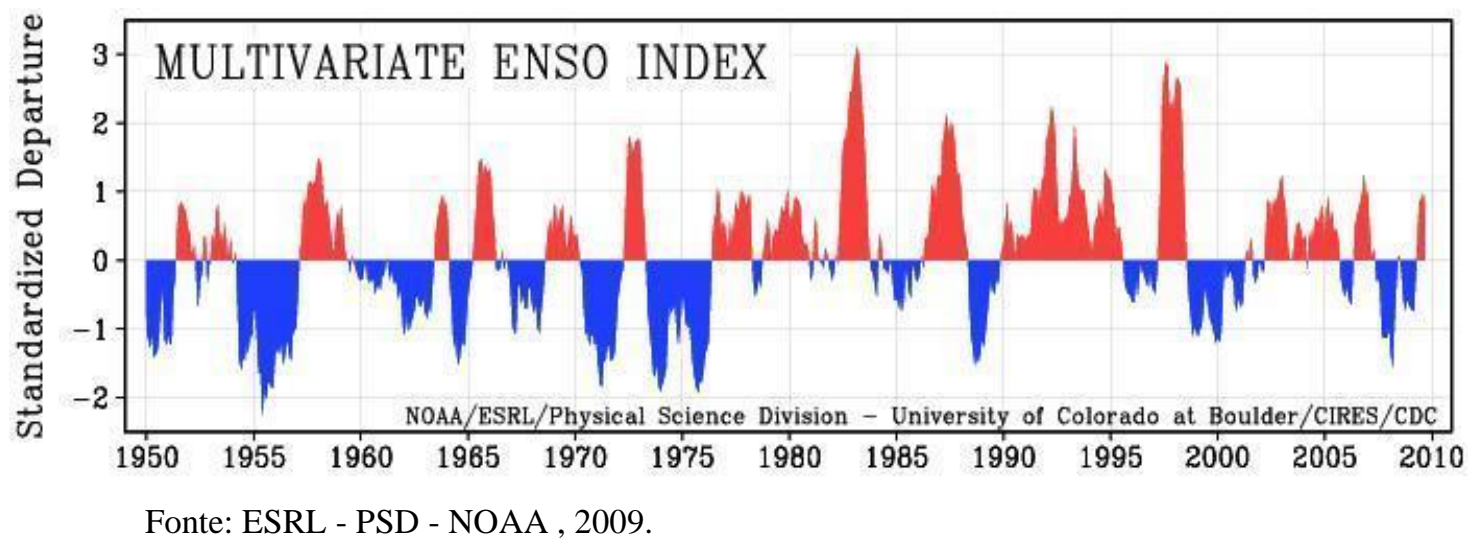

Figura 1: Ocorrência de ENOS, El Niños e La Niñas, entre 1950 e 2009.

A fase quente do ENOS, ou El Niño, caracteriza-se pela elevação da temperatura das águas superficiais (TSM) do Oceano Pacífico Equatorial, correspondendo às secas no Nordeste do Brasil, redução das chuvas na Amazônia e aumento da precipitação e da temperatura no Sul; a temperaturas elevadas no nordeste e noroeste dos EUA, Sul da Austrália, Japão e África do Sul (OLIVEIRA, 1999).

Inversamente ao El Niño, na fase La Niña ocorre redução da TSM no Oceano Pacífico equatorial. As regiões afetadas pela La Niña podem se diferenciar do El Niño. No Sul do Brasil ocorre frio e períodos de seca e no Nordeste maior precipitação; o frio intensifica-se sobre o Japão, Noroeste dos EUA e África do Sul. A periodicidade curta e a 
magnitude dos ciclos ENOS os tornam perceptíveis e relevantes às atividades socioeconômicas.

Durante a Oscilação Decadal do Pacífico (ODP), a cada duas ou três décadas há uma inversão entre fases frias e quentes na temperatura superficiais do mar (TSM) entre o Oceano Pacífico tropical e extratropical, completando o ciclo em 50 a 60 anos (DEWES, 2007, p.21). Na fase fria da ODP diminui a TSM no Pacífico Tropical e eleva-se a TSM no Pacífico extratropical, Norte e Sul; na fase quente, essa configuração da TSM se inverte.

Entre 1947-1976 ocorreu uma fase fria da ODP, acarretando frio intenso e fortes nevascas na Europa. Duas fases quentes da ODP aconteceram de 1925 a 1946, e de 1976 a 1998, que trouxeram secas aos EUA, chuvas intensas e calor à Europa (FIGURA 2). Nas fases frias da ODP predomina a ocorrência de La Niña e na fase quente predominam os El Niños. Há indícios de a ODP entrar na fase fria em duas décadas, o que traria aumento da freqüência de La Niñas e redução de El Niños (JISAO, 2012).

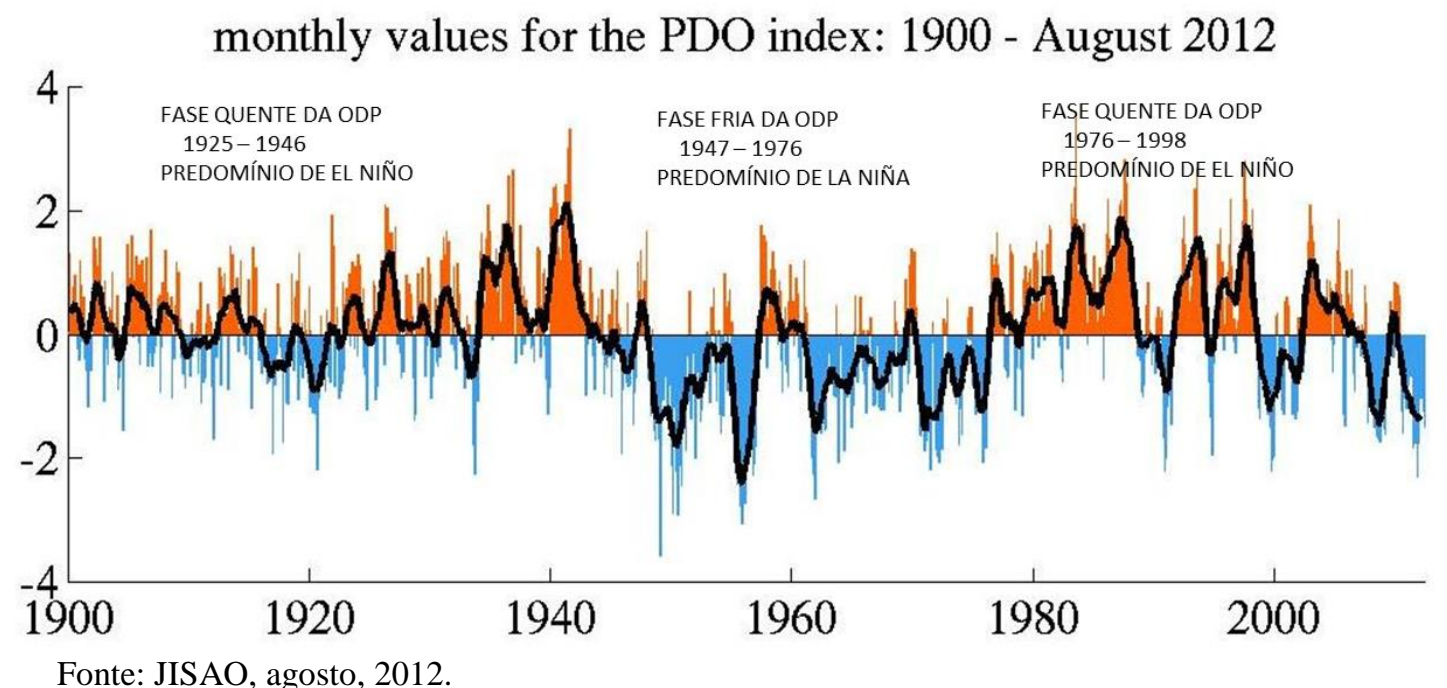

Figura 2: Períodos quentes e frios da evolução mensal da Oscilação Decadal do Pacífico (ODP), de 1900 a agosto de 2012.

Ciclos ODP são pouco perceptíveis durante uma vida humana, mas são evidentes nos gráficos e na história das civilizações. Há vestígios de ocorrência de PDO em anéis de arvores, com registros nos últimos dois mil anos. Essas variações têm correlação com extensos períodos de secas no oeste dos EUA (FIGURA 3). 


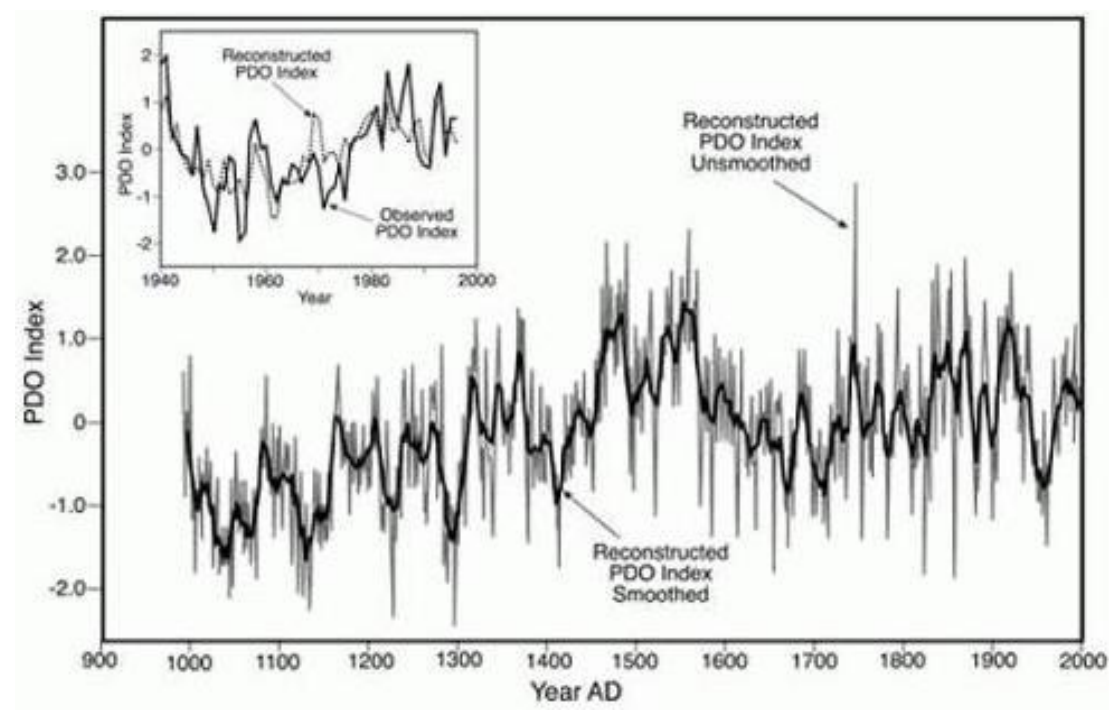

Fonte: ESRL - PSD - NOAA, 2009.

Figura 3: PDO em dois mil anos. Obtido a partir de anéis de árvores.

Aspectos astronômicos também interferem de modo cíclico e aleatório na dinâmica climática. Alguns de seus efeitos podem ser percebidos em períodos curtos. Entre as forçantes astronômicas destacam-se os ciclos solares, fenômenos de escala de décadas, e as oscilações na geometria orbital da Terra, ocorrida em dezenas de milhares de anos, conhecidas como ciclo de Milankovitch, cuja teoria é a mais coerente para explicar as glaciações pleistocênicas (SALGADO LABOURIAU, 1994).

Há assim variações no recebimento de energia pela Terra, a qual não é um sistema fechado. O Sol supre 99\% da energia que mantêm a vida na Terra (AYOADE, 1996, p.23). Entretanto, a energia eletromagnética e corpuscular emitida por ele não é constante, apresenta alterações, como em toda estrela. Apesar de não ocorrerem com exatidão, determinados ciclos solares são acompanhados por índices fundados, sobretudo, nas emissões de manchas solares, com períodos de 11, 22, 44, 77, 100 anos, séculos e até de curto prazo, que atuam como indutores externos das alterações climáticas, de grande interesse meteorológico (ALMEIDA, 2001, p.5-15). Não por acaso, povos conhecedores da astronomia no passado vincularam o Sol à divindades e estabeleceram calendários anuais a partir de suas observações, como os Maia e Inca.

O ciclo de 11 anos é o mais conhecido das atividades solares. Seu índice funda-se na emissão de manchas solares no período (FIGURA 4). Há correlação desses ciclos com o El ñino e a Oscilação Decadal do Pacífico - ODP (MOLION, 2006. p. 4; STOTT, 2003, p. 
4079). Houve um período de interrupção desse ciclo de onze anos de emissão de manchas solares. Esse período de menor intensidade de manchas solares é conhecido como Mínimo de Maunder, e ocorreu entre 1645 a 1715, num intervalo de 70 anos de baixa intensidades de manchas solares. Coincidiu com a pequena Idade do Gelo, período de invernos rigorosos e anos sem verão na Europa, de temperaturas médias baixas, evidenciado em pinturas com o Rio Tamisa congelado em Londres, e canais de Veneza com ocorrências de congelamento.

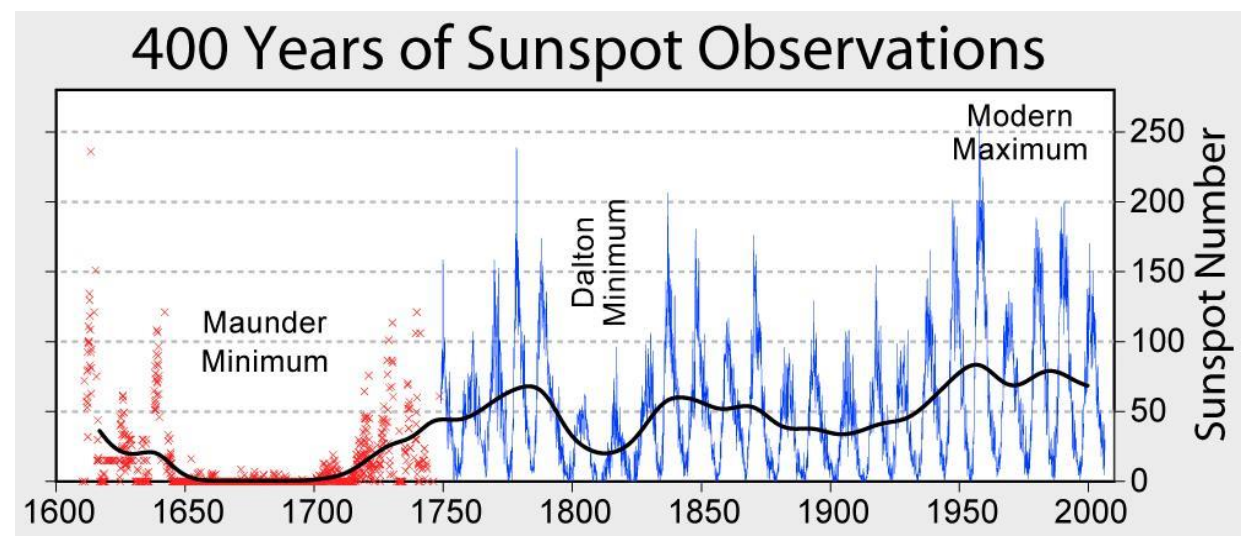

Fonte: STOTT et al (2003).

Figura 4: Quatrocentos anos de observação dos ciclos de atividades solares, registrado pela Academia de ciência da Bélgica.

Coincidências entre os ciclos das variáveis climáticas podem ampliar, ou anular, a magnitude dos fenômenos climáticos, acarretando extremos: furacões, tornados, secas e períodos chuvosos prolongados, e até fazer colapsar civilizações que desconheçam tais eventos, ou tenham poucos recursos tecnológicos, materiais e/ou financeiros (DIAMOND, 2005, p. 28). Os Maia, Inca, Asteca, os romanos e os egípcios lidaram com alterações climáticas, intensas e prolongadas ondas de calor e de frio. Há muitos relatos acerca do Período de Aquecimento Medieval, entre 800 e 1350 d.C., o qual trouxe maior umidade e calor à Europa e secas ao Mediterrâneo; e da Pequena Idade do Gelo, entre 1550 e 1850, com secas, nevascas e frio intenso à Europa (SANT'ANNA NETO \& NERY, 2005, p. 33; FIGURA 5). Como visto acima, esse período frio coincidiu com a fase de menor emissão de manchas solares conhecida, ocorrida entre 1645 a 1715. 


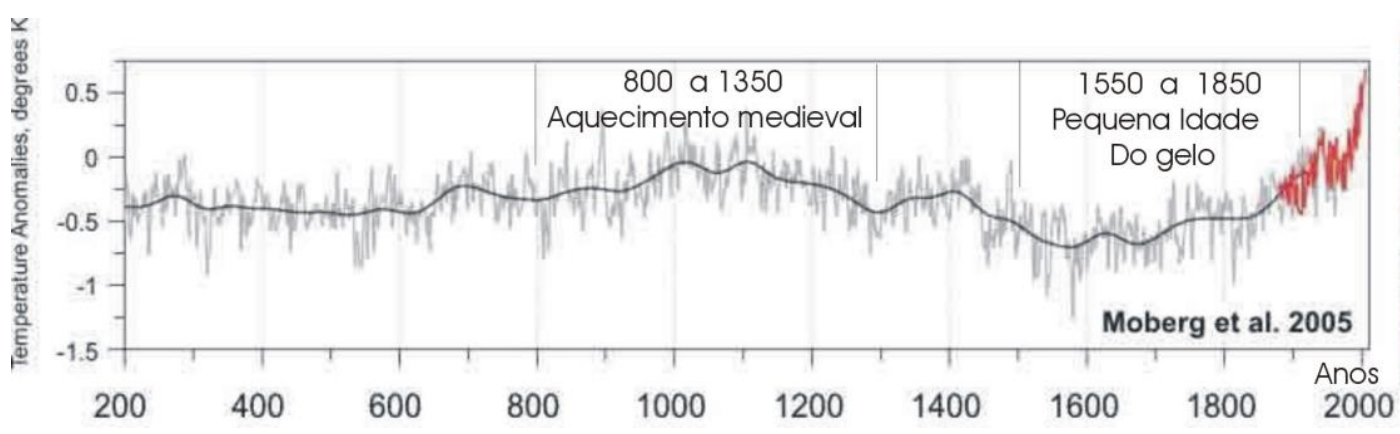

Fonte: MOBERG et al, 2005.

Figura 5: Variação da temperatura média global entre 200 e 2005 dC.

Entre os fenômenos astronômicos correlacionados à dinâmica climática de longa duração estão as variações na geometria orbital terrestre, principal responsável pela maioria dos períodos glaciais e inter-glaciais do Pleistoceno, mas não as únicas causas, pois o clima resulta da interação de dezenas de variáveis. Essas variações orbitais induziram glaciações que duraram em torno de trinta mil anos, e fases quentes e úmidas de dez mil (LABOURIAU, 2007, p. 1-2). Nesse período se destacaram as glaciações Nebascan (Günz), Kansan (Mindel), Ilinoian (Riss), Wisconsin (Würm) (FIGURA 6). É consenso na antropologia que o Homo Sapiens adquiriu suas características nesse período de intensa modificação climática, há mais de 180 mil anos AP. O que significa dizer que nossa espécie foi capaz de atravessar fortes variações climáticas. 


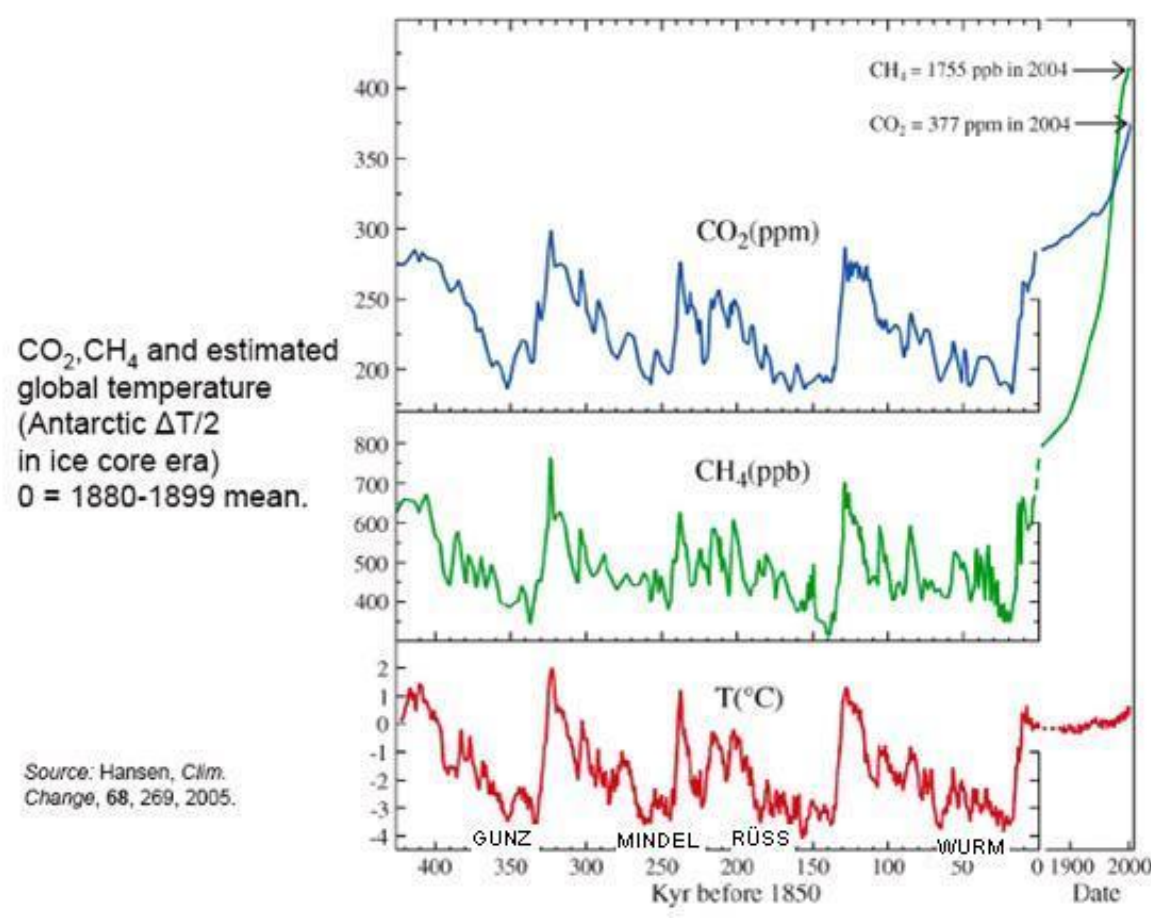

Fonte: HANSEN, 2005, p. 269.

Figura 6: Temperatura média global, nível de $\mathrm{CO}_{2}$ e metano na atmosfera nos últimos 425.000 anos.

Milutin Milankovitch demonstrou que as glaciações Quaternárias estiveram associadas a uma combinação de três variáveis astronômicas do sistema Terra-Sol-Lua: alteração no movimento de precessão dos equinócios, em intervalos de 11 mil e 22 mil anos; mudanças na obliquidade do plano da eclíptica, com periodicidade de 41 mil anos; e variações na excentricidade da orbita elíptica da Terra, com ciclos de 92 mil anos (DEWES, 2007, p. 2; FERREIRA, 2002, p 13; FIGURA 7). 


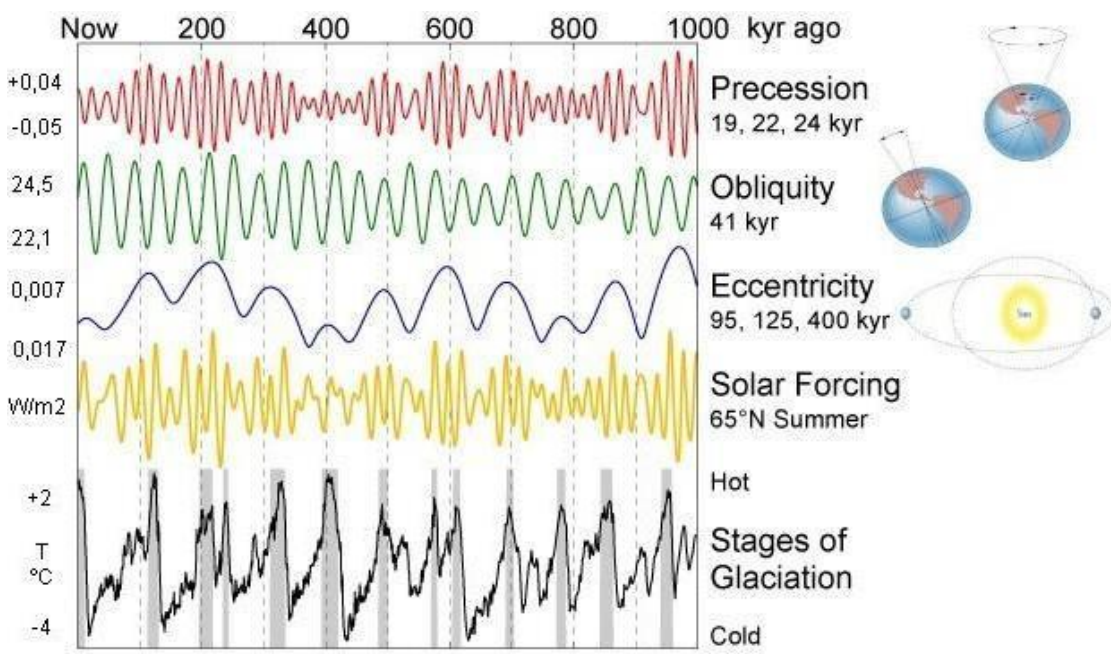

Fontes: LISIECKI, L. E. and RAYMO, M. E. (2005). QUINN, T.R. et al (1991). HAYS, J. D., et al (1976).

Adaptação: LOIOLA, S. A, 2009.

Figura 7: Variação orbital da Terra, forçante solar e glaciações em um Milhão de anos

Contudo, glaciares dificilmente ocorreriam somente devido à variação orbital terrestre. Um conjunto de fatores retroalimentados interfere conjuntamente. Sob menor forçante solar, a ampliação da superfície com gelo aumenta o albedo terrestre que, em conjunto com a fixação de gases estufa na atmosfera, no oceano e no gelo, reduzem o efeito estufa, intensificando o resfriamento (LISIECKI \& RAYMO, 2005). Físicos da atmosfera tem demostrado relações entre campo magnético terrestre e raios cósmicos na formação de nuvens de baixa altitude, bem como a influencia dos aerossóis emitidos pelas florestas tropicais na formação de nuvens e precipitação.

Apesar da predominância de eventos cíclicos, nem toda mudança na dinâmica climática é periódica, tampouco os eventos cíclicos seguem intervalos exatos e totalmente previsíveis. Quedas de meteoros, vulcanismo, atividades geológicas, processos circulatórios atmosféricos e oceânicos, e atividades biológicas também causaram alterações climáticas abruptas no passado em períodos de anos e décadas (FERREIRA, 2002, p.8-15).

São conhecidas 26 mudanças climáticas abruptas ocorridas no Pleistoceno Superior, entre 80 mil e 10 mil anos atrás, durante o período glacial Würm (FIGURAS 8 e 9). Vinte delas, denominadas ciclos Dansgaard-Oeschger (D-O), são intervaladas de mil a três mil anos; e seis ciclos Heinrich $(\mathrm{H})$, em períodos de sete mil a treze mil anos, revelados pelas 
sondagens GISP2 e DSDP 609 na sedimentação no leito oceânico, a partir de medição de isótopos de $18 \mathrm{O}$ e deposição de carbonato (FERREIRA, 2002, p. 12; GROOTES et al., 1993; BOND, G. C. \& LOTTI, 1995; FIGURA 13). ${ }^{5}$

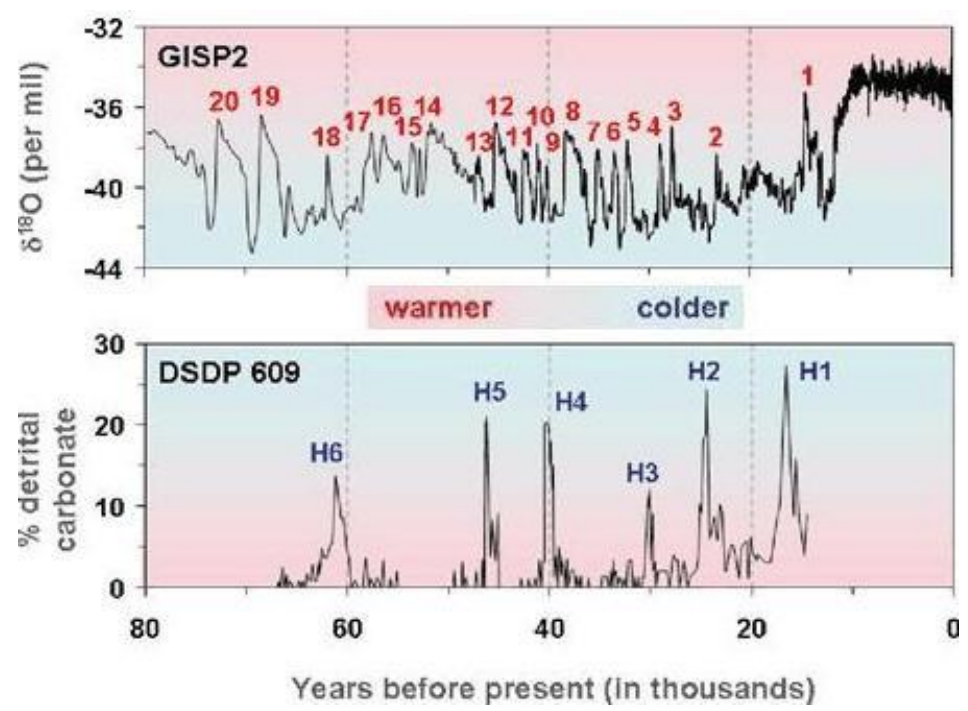

Fontes: GROOTES et al., (1993); BOND, G. C. \& LOTTI (1995).

Figura 8: Eventos abruptos D-O e $\mathrm{H}$ registrados em isótopos de $\mathrm{O}^{18}$ e carbonato no gelo da Groelândia, Hemisfério Norte, Oceano Atlântico, desde 80 mil anos AP.

No Hemisfério Sul foram encontrados evidências dos eventos D-O e H, no projeto EPICA (European Project for Ice Coring in Antarctica) em núcleos de gelo do Domo C, cuja datação recuou até 80 mil anos AP, obtidos pela estimativa de temperatura a partir medições de Deutério. Devido a grande massa de água dos oceanos do Sul, os efeitos desses eventos foram menos intensos (FIGURA 9).

Tanto os ciclos D-O quanto os $\mathrm{H}$ se iniciaram de forma rápida, décadas, ou em um ou dois séculos, e terminaram de modo gradual. Sob um clima árido como o do glacial Würm e suas mudanças repentinas, o cultivo agrícola seria improvável (FLANERY, 2007, p. 87).

\footnotetext{
${ }^{5}$ Sondagem DSDP 609 (Deep Sea Drilling Project Site) realizada no leito oceânico do Atlântico Norte, com medições da deposição de carbonato. Sondagem GISP2 Greenland Ice Sheet Project, realizada em núcleos de gelo na Groelândia com medição de isótopos de Oxigênio. 


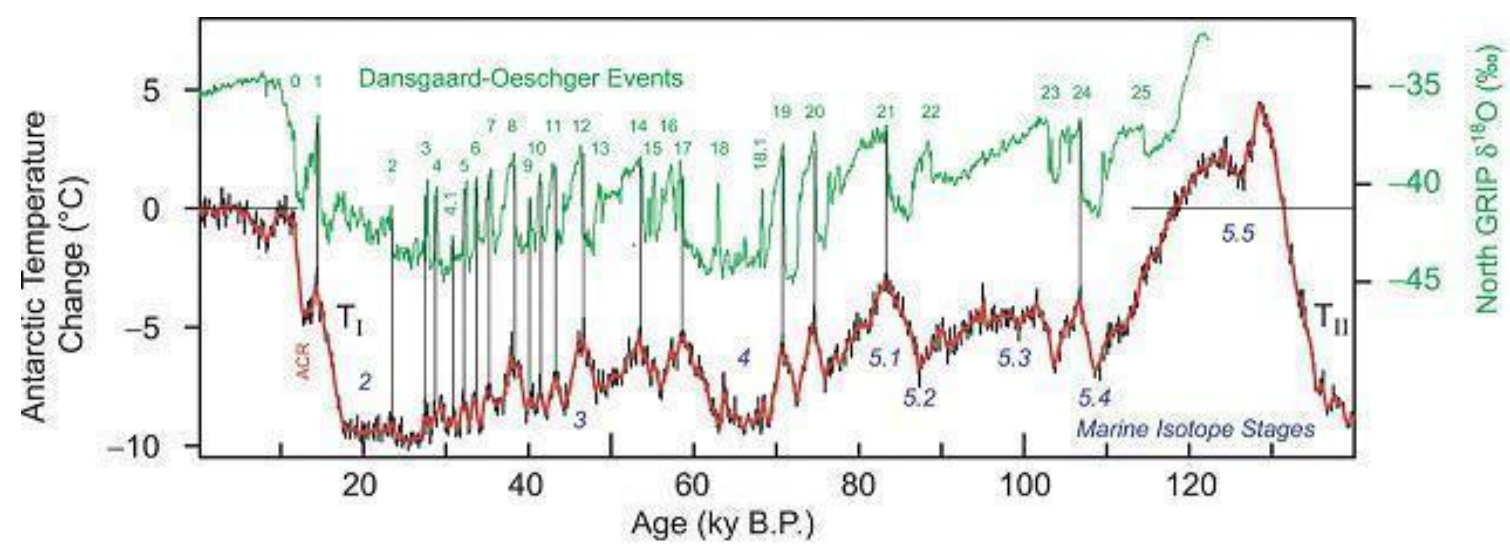

Fonte: JOUZEL et al, 2007.

Figura 9: Correlação entre a temperatura nos últimos 80 mil anos no Domo C, na Antártica, e os eventos D-O.

Apesar da instabilidade climática, a população humana ampliou a demografia e se expandiu pelo globo em torno de 40 mil anos $\mathrm{AP}$, o que remete a inúmeras indagações acerca dos motivos dessa expansão (CAPRA, 2004, p. 204-207). A mais conhecida mudança climática abrupta é o Younger Dryas, Era glacial anômala ocorrida entre 12.900 e 11.500 anos AP, que teve duração e intensidade assemelhada a um episódio Heinrich (FIGURA 10; ADAMS et al., 1999, p.14).

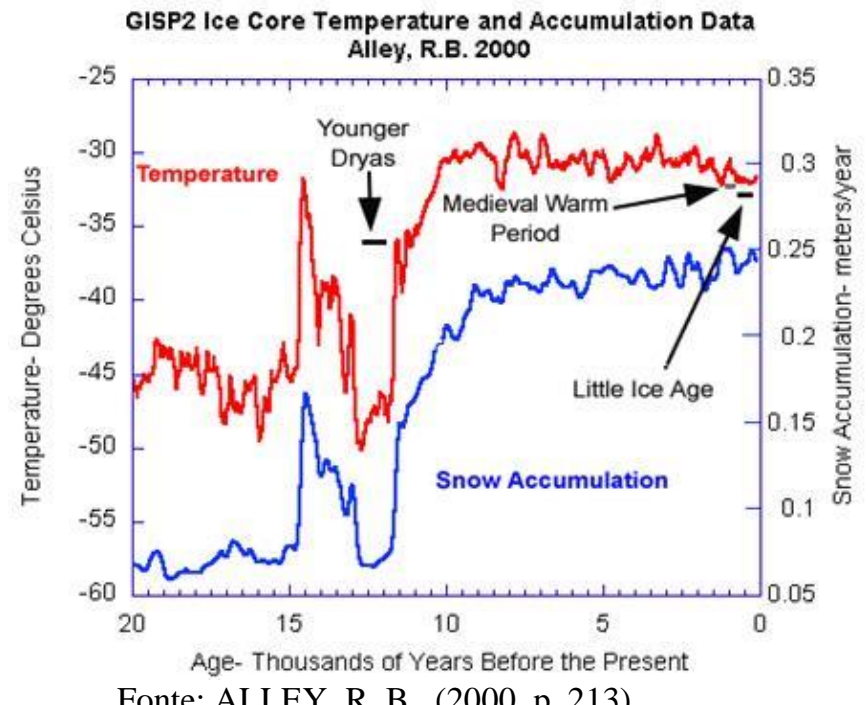

Figura 10: Período glacial Younger Dryas, entre 12.900 e 11.500 anos AP.

Após o glacial Dryas se estabeleceu o "longo verão", ou o interglacial que perdura até os dias atuais (FLANERY, 2007, p. 87). E forte a correção entre a mudança abrupta do Younger Dryas e a queda de um meteoro ou cometa, com vestígio de vidro e diamantes 
fundidos, encontrados por geólogos, geofísicos e medições astronômicas em toda América, sobretudo no norte, bem como na Europa. As datações da queda desse corpo são convergentes e precisas com a mudança brusca no clima, 12900 anos AP. Antes desse evento a Sibéria possuía vegetação arbustiva, habitada por mamutes e mega fauna. Desde então se tornou congelada. Esse evento provavelmente respondeu pela mudança climáticoecológica que teria levado a extinção da megafauna em todo globo.

Como as sociedades humanas responderam a essa mudança brusca é objeto dessa pesquisa.

Outro aspecto importante nas variações climáticas é a circulação das correntes oceânicas. Os modelos de circulação oceânica sugerem que um aumento do fluxo de água doce para o Ártico pode reduzir a circulação das águas superficiais para as profundezas do Atlântico Norte, e até interromper a haloclina polar, provocar severa redução na circulação termohalina, acarretando alterações climáticas globais (ADAMS et al., 1999, p.17). Fenômenos apontados como indutores dos eventos abruptos D-O, H. Porém as hipóteses sobre as forçantes que atuaram nesses eventos são inconclusas. Um enfraquecimento da circulação na termohalina diminuiria a corrente do Golfo, causaria o resfriamento da Europa, e a elevação de gases estufa e da temperatura global, desencadeando processos oceânico-atmosféricos retroalimentados e uma instabilidade climática imprevisível.

Interações atmosfera-oceano respondem por grande parte da dinâmica climática global. Sabe-se pouco ainda sobre a influência da circulação oceânica profunda nesse processo, mas são conhecidas as principais correntes que caracterizam a circulação termohalina (SOUZA, 2008, p. 138; RAHMSTORF, 2002; FIGURA 11). 


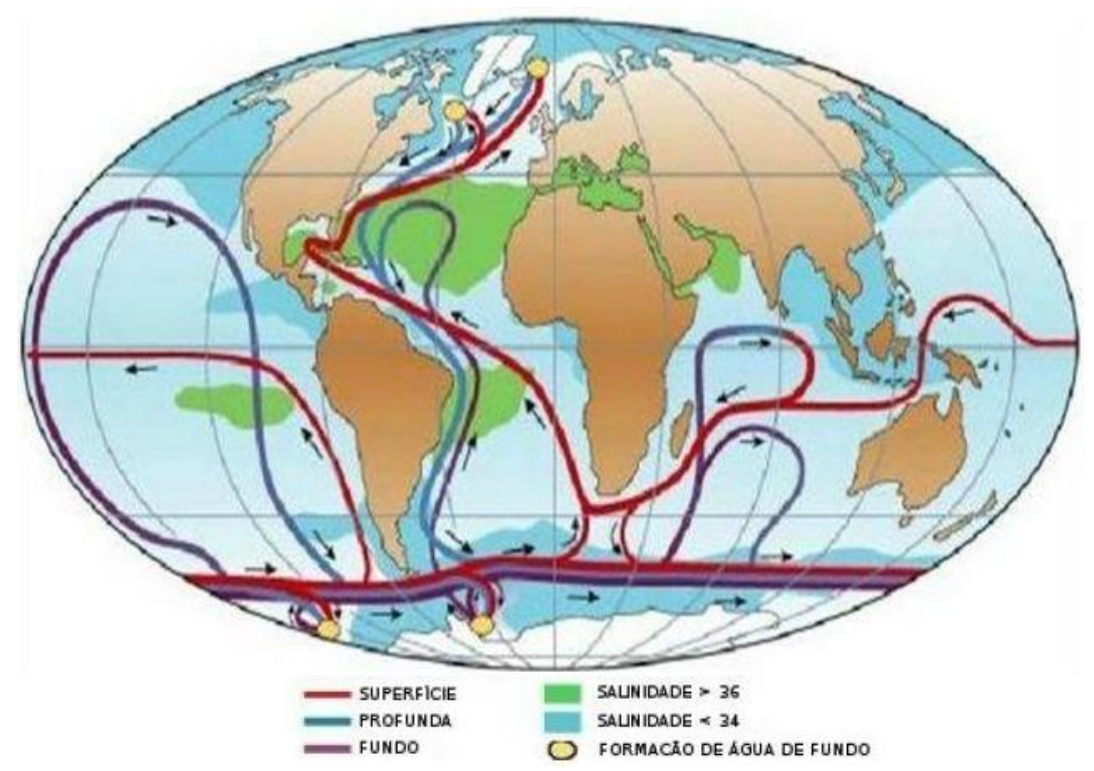

Fonte: RAHMSTORF, 2002.

Figura 11: Principais caminhos superficiais, fundo e profundo da circulação termohalina.

Embora a atmosfera tenha maior volume, as interações superficiais atmosferaoceano são influenciadas em grande parte pela capacidade térmica e a inércia dos oceanos. A circulação oceânica leva de 200 a 1800 anos para completar um circuito de revolvimento, de modo que, perturbações nesse sistema têm implicações na redistribuição de energia nos processos climáticos por longo tempo (SOUZA, 2008, p. 8).

Durante as mudanças climáticas, um "portal mágico" de ocorrência de fenômenos atmosféricos extremos pode ser aberto assim que atingido o limiar de transição telecinésico a um novo estado, trazendo instabilidade aos ritmos climáticos sazonais, ciclones, longos períodos de seca e chuvas, tempestades e alterações ecológicas abrangentes (FIGURA 12; FLANERY, 2007, p.109). ${ }^{6}$

Severas mudanças climáticas ocorreram no passado distante e recente da Terra, e motivado debates ao entendimento de questões complexas como a dinâmica climática global. Entretanto, independente de ser induzida por atividades humana ou por outras forças, o ritmo climático global nos último $500 \mathrm{mi}$ de anos não seguiu um padrão,

\footnotetext{
${ }^{6}$ Telecinesia atmosférica é o fenômeno físico que descreve a capacidade de a atmosfera de mudar de estado. Quando acrescida ou diminuída a energia circulante, a atmosfera pode dar saltos a novos limiares, fazendo aparecer fenômenos extremos em vários lugares. Essa passagem a um novo estado é popularmente denominada "porta mágica" (Ver Flanery, 2007, p. 109).
} 
indicando que cenários projetados por modelos podem falhar e induzir a equívocos históricos irreparáveis.
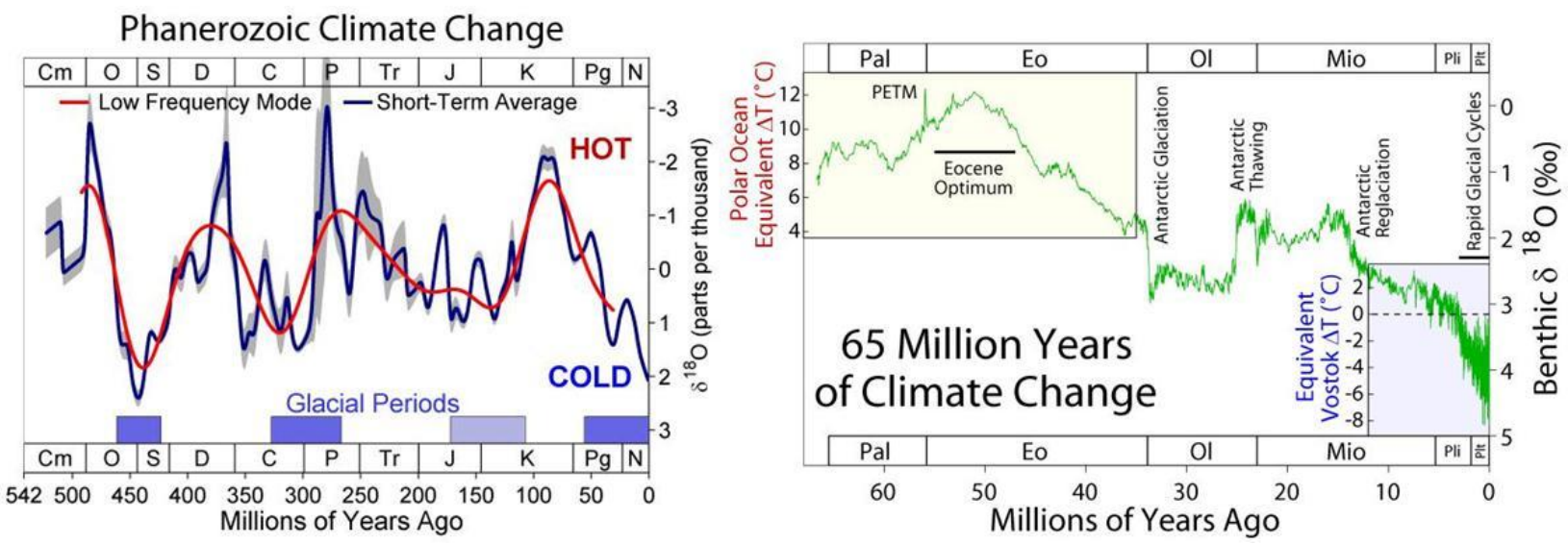

Fonte: NOAA, 2009

Figura 12: Inconstância das variações climáticas globais nos últimos 500 MI de anos

\section{RESULTADOS E DISCUSSÃO}

A dinâmica paleoclimática é totalmente anômala, sugere a imponderabilidade climática: mudanças abruptas, aleatórias, severas não podem ser previstas. Há momentos que o tempo entre uma glaciação e uma inter-glaciação podem ser menores que 50 anos. No caso do Younger Dryas, há 12900 anos um período glacial ocorreu em semanas ou meses. Fundados nesta constatação partiu-se para a construção de uma abordagem teórico conceitual para lidar com a imponderabilidade climática.

Tal abordagem é denominada Painel da Sustentabilidade Adaptativa, estruturado em três planos simultâneos para as sociedades lidarem com as alterações futuras do clima, apoiado numa abordagem evolutiva e na tese da imponderabilidade climática no longo tempo. Todos os planos encontram-se centrados na busca da adaptação pró-ativa, ou da sustentabilidade adaptativa, aos prováveis cenários: Plano A, voltado ao aquecimento global; Plano B, dedicado ao resfriamento global; e Plano C, para casos de instabilidade climática. Entre as medidas pode-se adotar de início: Adoção de tecnologias simples e 
flexíveis; Forçar a passagem par a sociedade da informação e dar maior visibilidade as iniciativas eficazes já adotadas. Entre outras medidas pode-se adiantar:

Dstimulo a implantação e intercambio de Centros Avançados de Transdisciplinaridade nas Universidades para pensar pro-ativamente a adaptação aos cenários imponderáveis de mudanças climático abruptas severas.

Fomentar a pesquisa e o ensino das mudanças climático ocorridas no passado e as respostas sociais.

Estabelecer entidade supranacional entre ONGs, Institutos de pesquisas, Sociedades, empresas para gerir um Painel da Sustentabilidade Adaptativa.

Adoção de medidas imediatas globais em pesquisa e inovação tecnológica de auto grau de sustentabilidade e adaptação a qualquer cenário da variabilidade climática, tais como: Uso de Energias alternativas de baixo custo, baixa manutenção e impacto ambiental: eólica, geotérmica, solar, marés, biogás etc. e abandono do uso da energia nuclear. Arquitetura ecológica: permaculturas, isolação térmica de casas, cidades inteligentes etc. Adoção de sistemas agroecológicos e autossuficiência alimentar local. Retorno de sementes crioulas aos agricultores, supressão dos alimentos transgênicos, redução do uso de insumos. Investir em segurança alimentar, logística simplificada, com a adoção do plantio de tubérculos, indicado pela FAO-ONU, com baixo uso de energia. Produção local de alimentos, com uso de hortas em escolas, presídios e parques públicos a fim de disseminar uma cultura de autossuficiência na população.

\section{CONSIDERAÇÕES FINAIS}

A vulnerabilidade climático/ambiental se acentual à medida que desestruturamos os sistemas ecológicos exploramos do potencial ecológico além do seu limiar de resiliência. No entanto, independente da interferência ou não da ação humana a instabilidade, nãolinearidade, não-equilíbrio e as mudanças abruptas são característica dos sistemas terrestres.

A certeza da ocorrência de mudanças climáticas abruptas e severas no futuro enseja a preparação para atravessar cenários de instabilidades climáticas e eventos extremos, que de certo modo podem ser imprevisíveis. Exige reduzir o grau de vulnerabilidade climática 
das sociedades, elaborar medidas preventivas e preparar ações para respostas pró-ativas e imediatas, a fim de evitar, adaptar-se e mitigar impactos, com planejamento em nível global ou não. Para tanto, importa conhecer as consequências das mudanças ocorridas no passado, sua extensão quais respostas as sociedades deram as condições severas definidas pelas mudanças climáticas.

\section{REFERÊNCIAS BIBLIOGRÁFICAS}

ADAMS, Jonathan et al. Sudden climate transitions during the Quaternary. Progress in Physical Geography. n. 23, 1999, p. 1-36.

ALLEY, Richard B. The Younger Dryas cold interval as viewed from central Greenland. Quaternary Science Reviews. v. 19, n. 1-5, Jan. 2000, p. 213-226.

ALMEIDA, Antônio Carlos Aido de. Estudo das correlações entre a atividade solar e processos atmosféricos. $89 \mathrm{f}$. Dissertação (Mestrado em Física). Instituto de Física, Departamento de Raios Cósmicos (DRCC), Universidade Estadual de Campinas UNICAMP, 2001.

BOND, G. C. \& LOTTI, R. Iceberg discharges into the North Atlantic on millennial time scales during the last glaciation. Science, n. 267, 1995, p. 1005-1010.

CAPRA, Fritjof. A teia da vida. São Paulo: Cultrix, 2004.

CHAMBERS, F. M. (Org.). Climate change and human impacto on the landscape: studies in paleoecology and environmental archeology. Londres: Chapman and Hall, 1994.

CLAVAL, Paul. As abordagens da geografia cultural. In: CASTRO, Iná E. de; GOMES, P. C. da C.; CORREA, R. Lobato (Org.). Explorações Geográficas: percursos no fim do século. Rio de Janeiro: Bertrand Brasil, 1997. p. 89-118.

COSTA e SILVA, Alberto da. A enxada e a lança: A África antes dos portugueses. Rio de Janeiro: Nova Fronteira, 1996.

CROWLEY, Thomas J. \& NORTH, Gerald R. Paleoclimatology. Nova York: Ed. Universidade de Oxford, 1991.

DAWKINS, Richard. A grande história da Evolução: na trilha dos nossos ancestrais. São Paulo: Companhia das letras, 2009.

DIAMOND, Jared. Colapso: Como as sociedades escolhem o fracasso ou o sucesso. Rio de Janeiro: Ed. Record, 2005.

ESRL - PSD - NOAA. Earth System Research Laboratory - Physical Sciences Division Multivariate ENSO Index (MEI). Disponível em:

<http://www.esrl.noaa.gov/psd/people/klaus.wolter/MEI/\#comparison> Acessado: Setembro de 2012. 
FAGAN, Brian. O aquecimento global: A influência do clima no apogeu e declínio das civilizações. São Paulo: Larousse do Brasil, 2009.

FERREIRA, A. de Brum. Variabilidade climática e dinâmica geomorfológica. Publicações da Associação Portuguesa de Geomorfólogos, Vol. 1, APGeom, Lisboa, p.7-15. 2002.

FLANNERY, Tim. Os senhores do clima: Como o homem está alterando as condições climáticas e o que isso significa para o futuro do planeta. Rio de Janeiro: Record, 2007.

GROOTES, P.M. et al. Comparison of oxygen isotope records from the GISP2 and GRIP Greenland ice cores. Nature, n. 366, 1993, p. 552-554.

JISAO JISAO (Joint Institute For de Study of the Atmosphere e Clime). Monthily values for PDO Index: 1900 - August 2012. Diponível: <http://jisao.washington.edu/pdo/> Acessado: setembro de 2012.

JOUZEL, J. et al. Orbital and Millennial Antarctic Climate Variability over the Past 800,000 Years. In: Science, v. 317, n. 5839, Ago, 2007, p.793-797.

KIPNIS, Renato \& SCHEEL-YBERT, Rita. Arqueologia e paleoambientes. In: SOUZA, Célia Regina de G. OLIVEIRA, Antonio M.; SUGUIO, Kenitiro; OLIVEIRA, Paulo E. de (Orgs.). Quaternário do Brasil. Ribeirão Preto: Holos, 2005, p. 343-362.

LEWIN, Roger. Evolucão humana. Sao Paulo: Atheneu, 1999.

LOIOLA, Sérgio Almeida. Do espaço e tempo ao espaço-tempo: dimensões e marcas. Geografia - Associação de Geografia Teorética - AGETEO), v. 35, n. 1, jan - abr, 2010a, p $5-35$.

Objetos, ações e processos naturais: de marcadores espaço-temporais a memórias socioambientais. Revista do Departamento de Geografia da USP - USP, Vol. 21, 2011, p.66-90.

LOWE, J.J. \& WALKER, M.J.C. Reconstructing Quaternary environments. London: Longmans, 1997.

MATURANA, Humberto \& VARELA, Francisco J. A arvore do conhecimento: as bases biológicas da compreensão humana. São Paulo: Palas Athena, 2005.

MENDONÇA, Francisco; DANNI-OLIVEIRA, Inês Moresco. Climatologia: noções básicas e climas do Brasil. São Paulo: Oficina de Textos, 2007.

MOLION, L. C. B.. Aquecimento global, El Niños, manchas solares, vulcões e oscilação decadal do Pacífico. Climanalise, Cachoeira Paulista, Ano 3, nº 1, 2006. Disponível em: 〈http://www6.cptec.inpe.br/revclima/revista/pdf/Artigo_Aquecimento_0805.pdf>. Acessado: 5/2009

NCDC - NOAA. National Climatic Data Center. National Oceanic Atmospheric Administration.

NOVELLO, Mario. Do Big Bang ao universo eterno. Rio de Janeiro: Jorge Zahar, 2010.

OLIVEIRA, G S. O El Niño e Você - o fenômeno climático. São José dos Campos: Transtec, 1999.

OLIVEIRA, Paulo E. et al. Paleovegetação e paleoclimas do quaternário do Brasil. In: SOUZA, Célia Regina de G.; OLIVEIRA, Antonio M.; SUGUIO, Kenitiro; OLIVEIRA, Paulo E. de (Orgs.). Quaternário do Brasil. Ribeirão Preto: Holos, 2005, p. 52-74. 
PEEL, M. C., FINLAYSON, B. L. \& MCMAHON, T. A. Updated world map of the Köppen-Geiger climate classification. Hydrological Earth System Science, n. 11, p. 1633$1644,2007$.

PRIGOGINE, Ilya. O fim das certezas: tempo, caos e leis da natureza. São Paulo: UNESP, 1996.

RAHMSTORF, Stefan. Ocean circulation and climate during the past 120000 years. Nature n. 419, 2002, p. 207-214.

SALGADO-LABORIOU, Maria Léa. Critérios e técnicas e técnicas para o Quaternário. São Paulo: Edgard Blücher, 2007.

SANTOS, Milton. Metamorfose do espaço habitado. São Paulo: Hucitec, 1997.

SANT'ANA NETO, João L. \& NERY, Jonas T. Variabilidade e mudanças climáticas no Brasil e seus impactos regionais. In: SOUZA, C. R. de G.; OLIVEIRA, A. M.; SUGUIO, Kenitiro; OLIVEIRA, Paulo E. de (Orgs.). Quaternário do Brasil. Ribeirão Preto: Holos, 2005.

SOUZA, João M. A. Correia de. A influência da atividade de meso-escala sobre o balanço termodinâmico do oceano austral. 159 f. Tese (Doutorado em Engenharia Oceânica), COPPE, Universidade Federal do Rio de Janeiro, 2008.

STOTT, Peter A.; JONES, Gareth S. and MITCHELL, John F. B.. "Do Models Underestimate the Solar Contribution to Recent Climate Change". Journal of Climate, $\mathrm{n}$. 16, 15 Dec. 2003, p. 4079-4093. Disponível em: < http://climate.envsci.rutgers.edu/pdf/StottEtAl.pdf> Acesso: Março de 2009.

SUGUIO, Kenitiro et al (Orgs). Paleoníveis do mar e paleolinhas de costa. In: SOUZA, Célia R. de G.; OLIVEIRA, A. M.; SUGUIO, Kenitiro; OLIVEIRA, Paulo E. de (Orgs.). Quaternário do Brasil. Ribeirão Preto: Holos, 2005, p. 114-129.

MARKGRAF, Vera. Interhemispheric climate linkages. San Diego: Publisher Academic Press, 2001.

URIARTE, Antón. Historia del clima de la Tierra. 2010. Livro. Disponível em: <http://www.herbogeminis.com/IMG/pdf/historia del clima de la tierra anton uriarte.pdf> Acessado em: janeiro de 2012.

WDC-NOAA: World Data Center for Paleoclimatology. Disponível em: http://www.ncdc.noaa.gov/paleo Acessado em: Setembro, 2012. 